\title{
Study on the Influencing Factors of the Energy - Saving and Environmental Protection Industry in Beijing
}

\author{
Zhang Yanfang \\ Department of Basic Education, Beijing University of Agriculture \\ Beijing, 102206
}

\begin{abstract}
The author's previous research shows that the development of the energy conservation and environmental protection industry in Beijing is at a moderate level throughout the country. This paper analyzes the statistics of Beijing from 2008 to 2015 by means of SPSS statistical software. Firstly, it analyzes various environmental protection factors and extracts the main factors, and then establishes a linear regression model with Beijing's regional production value as the dependent variable and each main factor as the independent variable. Finally, the result shows that Beijing's GDP is influenced by these factors including the industrial structure, science and technology, industrial pollution investment and the relationship between energy and emissions. To some extent, the result has a certain reference value for the development of energy-saving and environmental protection industry as well as the optimization and upgrading of industrial structure.
\end{abstract}

Keywords-The energy-saving and environmental protection industry; SPSS statistical software; Factor analysis; Linear regression

\section{INTRODUCTION}

The energy-saving and environmental protection industry refers to an industry that saves energy resources, develops the circular economy, and provides technological foundation and equipment support for environmental protection [1]. The development of the environmental protection industry in China has gradually been valued by the government, and the sound growth of the industry has become an important task.

China invests more and more in environmental protection. It can be seen that during the "12th Five-Year Plan" period, China's environmental protection industry produced an output value of about 4.5 trillion yuan, and employed a total of more than 30 million people. During the "13th Five-Year Plan" period, the annual growth rate of this industry is expected to exceed $20 \%$, and total social investment is expected to reach 17 trillion yuan, accounting for 3\% of GDP [2].

The development of domestic energy-saving and environmental protection industry starts late, and fewer related studies are done. Most of studies focus on analyzing the current status of the industry and discussing its development obstacles and prospects [3]. Yang Wensheng [4], Liu Jianqiu [1], and Liu Yifeng [5] studied the development of the environmental protection industry in Wuhan (a city in central
China), Hebei (a province in the northern part of China) and Guangzhou (a prosperous city in southern China) respectively, and Tao Jin [6] took Anhui (a province in southern China) as an example in 2015 to study and analyze the influencing factors of China's environmental protection industry in detail.

With the method of factor analysis, this paper analyzes the influencing factors of the energy-saving and environmental protection industry in Beijing and the effect of those factors on Beijing's GDP, establishing a linear regression model.

\section{MATHEMATICAL MODELS AND ANALYSIS}

\section{A. Materials and methods}

1) Data sources and variable settings

The data of this study comes from the statistical yearbook of the official website of the Beijing Municipal Bureau of Statistics. First, figure out the average of the raw data from 2008 to 2015, and then study the SPSS-standardized average as a variable. The variables are set as follows. As Beijing's environmental protection industry's total output value data is missing, Beijing's regional GDP will be analyzed as the dependent variable $y$. The independent variable $x_{1}$ represents investment for the industrial pollution treatment completion, taking 100 million yuan as the unit, $x_{2}$ represents the contribution rate of value added of the secondary industry, $x_{3}$ represents the contribution rate of value added of the tertiary industry, $x_{4}$ represents the total amount of energy consumption, $x_{5}$ represents the energy consumption level of regional GDP per unit, $x_{6}$ represents the amount of sulfur dioxide emissions, $x_{7}$ represents the amount of smoke and dust emissions, $x_{8}$ represents the amount of household garbage removal, $x_{9}$ represents the quantity of garbage innocuity disposal, $x_{10}$ represents the comprehensive utilization of general industrial solid waste, $x_{11}$ represents the amount of R\&D personnel in industrial enterprises above the designated scale, $x_{12}$ represents $\mathrm{R} \& \mathrm{D}$ funds of industrial enterprises above the 
designated scale, $x_{13}$ represents the patent application quantity of industrial enterprises above the designated scale, and $x_{14}$ represents technical market turnover.

\section{2) Introduction of analytical methods [7]}

\section{a) Factor analysis}

Factor analysis uses a few "main factors" to replace original variables, thereby reflecting the relationship between the original variables and the main factors. The KMO and Bartlett test of sphericity are needed to determine whether factor analysis can be performed. The main applications include the use of main factors instead of the original variables for regression analysis, cluster analysis, and discriminant analysis, etc.

\section{b) Regression analysis mathematical model}

Linear regression analysis is a statistical analysis method that studies the linear relationship between a dependent variable and one or more variables independent of each other. When the linear regression model is established, it needs a residual normal distribution test and a zero-hypothesis test of the regression coefficient.

\section{B. Data Analysis and Results}

The author's previous research shows that the development of environmental protection industry in Beijing is at a middle level throughout the country. On the one hand, as the national capital, Beijing integrates various resources and has irreplaceable advantages. On the other hand, with a large permanent and floating resident population in Beijing, as well as the rapid development of the economy, Beijing has met numerous practical difficulties in the environment protection. Therefore, it is necessary to study the relationship between economic development and environmental protection factors in Beijing.

\section{1) Factor analysis and linear regression}

Linear regression requires that each independent variable be independent of each other. Factor analysis, on the premise of retaining most of the original variable information, replaces a large number of highly correlated original variables with a few unrelated factors [3].

Firstly, use factor analysis to simplify numerous independent variables $\left.x_{i}(i=1,2, \ldots, 6,8, \ldots, 14)\right)$ into 3 main factors independent of each other. Secondly, take these 3 main factors $F_{1}^{\prime}, F_{2}^{\prime}, F_{3}^{\prime}$ as independent variables and the regional GDP $y$ as the dependent variable to build a linear regression model.

\section{a) Factor analysis}

After the 14 economic indicators are processed by the SPSS data processing system and validated by the KMO and Bartlett test of sphericity, factor analysis can be performed. The principal component method is used to extract factors, thereby obtaining the eigenvalues, contribution rates and cumulative contribution rates of the correlation coefficient matrix (Table 1). The cumulative variance contribution rate of 3 factors reaches $95.963 \%$, greater than $85 \%$, so the number of main factors is determined as three. The 3 main factors are used to represent the original 14 factors for linear regression and they include $95.963 \%$ of the information of the original 14 independent variables.

TABLE I TOTAL VARIANCE EXPLAINED

\begin{tabular}{|c|c|c|c|c|c|c|c|}
\hline \multirow[t]{3}{*}{ Component } & \multicolumn{3}{|c|}{ Initial Eigenvalues } & $\begin{array}{l}\text { Extraction Sums } \\
\text { Loadings }\end{array}$ & of Square & \multirow{2}{*}{\multicolumn{2}{|c|}{$\frac{\text { Loadings }}{\%}$}} \\
\hline & \multirow[b]{2}{*}{ Total } & \multicolumn{2}{|l|}{$\%$} & & & \\
\hline & & Variance & Cumulative & $\%$ Total $\%$ of Variance & Cumulative $\%$ & Total Variance & Cumulative \% \\
\hline 1 & 19.817 & 70.121 & 70.121 & 9.81770 .121 & 70.121 & 9.12665 .183 & 65.183 \\
\hline & 22.136 & 15.254 & 85.375 & 2.13615 .254 & 85.375 & 2.76519 .753 & 84.936 \\
\hline & 31.482 & 10.589 & 95.963 & 1.48210 .589 & 95.963 & 1.54411 .028 & 95.963 \\
\hline & $\begin{array}{rr}4.369 \\
-r y\end{array}$ & 2.634 & 98.597 & & & & \\
\hline & 5.116 & .831 & 99.428 & & & & \\
\hline & 6.062 & .442 & 99.870 & & & & \\
\hline & 7.018 & .130 & 100.000 & & & & \\
\hline dimension $0^{8}$ & $83.230 \mathrm{E}-16$ & $2.307 \mathrm{E}-15$ & 100.000 & & & & \\
\hline & 9 2.809E-16 & $2.007 \mathrm{E}-15$ & 100.000 & & & & \\
\hline & 101.096E-16 & $7.828 \mathrm{E}-16$ & 100.000 & & & & \\
\hline & $11-5.932 \mathrm{E}-1$ & 7-4.237E-16 & 100.000 & & & & \\
\hline & $12-1.528 \mathrm{E}-1 \mathrm{C}$ & $6-1.091 \mathrm{E}-15$ & 100.000 & & & & \\
\hline & $13-2.762 \mathrm{E}-1 \mathrm{C}$ & $6-1.973 \mathrm{E}-15$ & 100.000 & & & & \\
\hline & $14-6.537 \mathrm{E}-1 \mathrm{C}$ & $6-4.669 E-15$ & 100.000 & & & & \\
\hline
\end{tabular}


The loading matrix is obtained by varimax orthogonal rotation of initial factors (cf. Tab. 2). The loading matrix shows that there are 9 variables with a higher load on the first factor: the contribution value of the secondary industry $x_{2}$, the contribution value of the tertiary industry $x_{3}$, the total energy consumption $x_{4}$, the unit GDP energy consumption level $x_{5}$, sulfur dioxide emissions $x_{6}$, the amount of $\mathrm{R} \& \mathrm{D}$ personnel in industrial enterprises above the designated scale $x_{11}, \mathrm{R} \& \mathrm{D}$ funds of industrial enterprises above the designated scale $x_{12}$, patent applications of industrial enterprises above the designated scale $x_{13}$, technical market turnover $x_{14}$. Therefore, the first factor mainly explains these variables. Let the first factor $F_{1}^{\prime}$ be the basic comprehensive factor (industrial structure, total energy consumption, sulfur dioxide emissions, investment and achievements of industrial enterprise research and experimental development, as well as marketization degree); there are 3 variables with a higher load on the second factor: investment for the industrial pollution treatment completion $x_{1}$, smoke and dust emissions $x_{7}$, as well as the amount of household garbage removal $x_{8}$. Let the second factor $F_{2}^{\prime}$ be the pressure factor (investment for pollution control completion and environmental pollution emissions); there are 2 variables with a higher load on the third factor: quantity of garbage innocuity disposal $x_{9}$, and the comprehensive utilization amount of general industrial solid waste $x_{10}$. Let the third factor $F_{3}^{\prime}$ be the capacity factor (environmental processing capacity).

TABLE II ROTATED COMPONENT MATRIX A

\begin{tabular}{|c|c|c|c|}
\hline & \multicolumn{3}{|c|}{ Component } \\
\hline & 1 & 2 & 3 \\
\hline \multicolumn{2}{|l|}{$\begin{array}{l}\mathrm{x} 1 \text { investment for the industrial pollution treatment completion (taking } 10.210 \\
\text { thousand yuan as the unit) }\end{array}$} & .888 & .221 \\
\hline X2 contribution rate of value added of the secondary industry & .986 & .095 & .021 \\
\hline $\mathrm{X} 3$ contribution rate of value added of the tertiary industry & .952 & .297 & -.019 \\
\hline $\mathrm{X} 4$ total amount of energy consumption & -.736 & -.632 & -.162 \\
\hline X5 energy consumption level of regional GDP per unit & .968 & .235 & -.007 \\
\hline X6 amount of sulfur dioxide emissions & -.967 & -.246 & .004 \\
\hline $\mathrm{X} 7$ amount of smoke and dust emissions(taking 1 ton as the unit) & .615 & -.709 & .166 \\
\hline $\begin{array}{l}\text { X8 amount of household garbage removal(taking } 10 \text { thousand ton as th } \\
\text { unit) }\end{array}$ & e. 571 & .813 & -.038 \\
\hline $\begin{array}{l}\text { X9 quantity of garbage innocuity disposal(taking } 10 \text { thousand ton as th } \\
\text { unit) }\end{array}$ & e. 322 & .223 & .843 \\
\hline x10 comprehensive utilization amount of general industrial solid waste & -.642 & -.107 & .717 \\
\hline $\begin{array}{l}\text { x11 R\&D personnel full-time equivalent in industrial enterprises above th } \\
\text { designated scale (per person per year) }\end{array}$ & e. 884 & -.098 & .434 \\
\hline $\begin{array}{l}\mathrm{x} 12 \mathrm{R} \& \mathrm{D} \text { funds of industrial enterprises above the designated scale(takin } \\
10 \text { thousand ton as the unit) }\end{array}$ & & .209 & .052 \\
\hline $\begin{array}{l}\text { x13 amount of patent applications of industrial enterprises above th } \\
\text { designated scale }\end{array}$ & e.966 & .050 & .147 \\
\hline $\mathrm{x} 14$ technical market turnover (taking 100 million yuan as the unit) & .952 & .288 & .032 \\
\hline
\end{tabular}


The factor score function is obtained by using the regression method, and the factor score matrix is shown in Table 3. The 3 main factors are denoted as a linear combination of 14 original indicators, and the relationship between each main factor and each independent variable of economic factors is shown in the form of an equation.

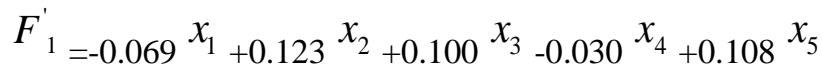

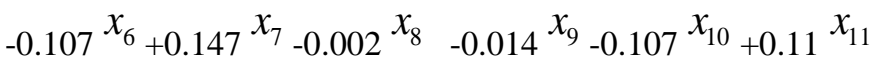

$$
\begin{aligned}
& 1+0.109^{x_{12}}+0.120^{x_{13}}+0.099^{x_{14}}
\end{aligned}
$$

TABLE III COMPONENT SCORE COEFFICIENT MATRIX

\begin{tabular}{|c|c|c|c|}
\hline & Comp & & \\
\hline & 1 & 2 & 3 \\
\hline $\begin{array}{l}\mathrm{x} 1 \text { investment for the industrial pollution treatment completion (taking } \\
10 \text { thousand yuan as the unit ) }\end{array}$ & 8.069 & .364 & .116 \\
\hline $\mathrm{X} 2$ contribution rate of value added of the secondary industry & .123 & -.057 & -.030 \\
\hline $\mathrm{X} 3$ contribution rate of value added of the tertiary industry & .100 & .036 & -.061 \\
\hline $\begin{array}{l}\text { X4 total amount of energy consumption } \\
\text { X5 energy consumption level of regional GDP per unit }\end{array}$ & $\begin{array}{l}-.030 \\
.108\end{array}$ & $\begin{array}{l}-.201 \\
.007\end{array}$ & $\begin{array}{l}-.061 \\
-.051\end{array}$ \\
\hline $\begin{array}{l}\text { X6 amount of sulfur dioxide emissions } \\
\text { X8 amount of smoke and dust emission (taking } 1 \text { ton as the unit) }\end{array}$ & $\begin{array}{l}-.107 \\
.147\end{array}$ & $\begin{array}{l}-.012 \\
-.377\end{array}$ & $\begin{array}{l}.050 \\
.104\end{array}$ \\
\hline $\begin{array}{l}\text { X9 amount of household garbage removal (taking } 10 \text { thousand ton as the } \\
\text { unit) }\end{array}$ & e-.002 & .301 & -.071 \\
\hline $\begin{array}{l}\text { x10 quantity of garbage innocuity disposal (taking } 10 \text { thousand ton as the } \\
\text { unit) }\end{array}$ & e-.014 & .044 & .545 \\
\hline x11 comprehensive utilization amount of general industrial solid waste & -.107 & -.002 & .510 \\
\hline $\begin{array}{l}\text { x12 R\&D personnel full-time equivalent in industrial enterprises abov } \\
\text { the designated scale(per person per year) }\end{array}$ & & -.142 & .256 \\
\hline $\begin{array}{l}\text { x13 R\&D funds of industrial enterprises above the designated } \\
\text { scale(taking } 10 \text { thousand yuan as the unit) }\end{array}$ & d.109 & -.006 & -.012 \\
\hline $\begin{array}{l}\text { x14 amount of patent applications of industrial enterprises above the } \\
\text { designated scale }\end{array}$ & e. 120 & -.078 & .056 \\
\hline x15 technical market turnover (taking 100 million yuan as the unit) & .099 & .031 & -.026 \\
\hline
\end{tabular}

Extraction Method: Principal Component Analysis. Rotation Method: Varimax with Kaiser Normalization. Component Scores.

$$
\begin{aligned}
& F_{2}^{\prime}=0.364^{x_{1}}-0.057^{x_{2}}+0.036^{x_{3}}-0.201^{x_{4}}+0.007^{x_{5}}
\end{aligned}
$$

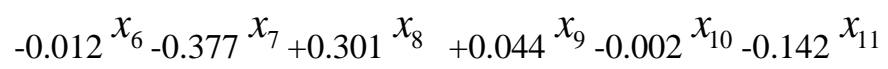

$$
\begin{aligned}
& 1-0.006^{x_{12}-0.078^{x_{13}}+0.031^{x_{14}}} \\
& F_{3}^{\prime}=0.116^{x_{1}}-0.030^{x_{2}}-0.061^{x_{3}}-0.061^{x_{4}}-0.051^{x_{5}} \\
& +0.050^{x_{6}+0.104}{ }^{x_{7}}-0.071^{x_{8}}+0.545^{x_{9}}+0.510 x_{10}+0.256 \\
& x_{11-0.012} x_{12}+0.056^{x_{13}-0.026^{x_{14}}}
\end{aligned}
$$

\section{b) Linear regression model}

The 3 main factors (basic comprehensive factor $F_{1}^{\prime}$, pressure factor $F_{2}^{\prime}$, and capacity factor $F_{3}^{\prime}$ ) are taken as independent variables, and the GDP is taken as the dependent variable, multiple linear regression is performed by means of
SPSS. The residual distribution histogram and the observation cumulative probability plot of the linear regression model (not shown) can all indicate that the residuals are normally distributed, which proves that the sample is indeed from the normal population. In the scatter plot of studentized deleted residuals standardized predictive value (not shown), the points are basically and evenly distributed above and below the straight line corresponding to the zero point of the vertical axis. Then we can naturally ascertain that the assumption of homogeneity of the variance is true. Therefore, the data in this model fully meet the condition for the normal distribution of residuals required by multiple linear regression.

All 3 variables enter the model by means of Enter method (a method that enables all variables to enter the model).

In the model description table (Table 4), the multiple correlation coefficient of the model is shown as $\mathrm{R}=0.997$, indicating that the 3 main factors have a strong linear relationship with the dependent variable ${ }^{y}$. The square of the complex correlation coefficient is $\mathrm{R} 2=0.994$, indicating that 
the regression equation explains the $99.4 \%$ variability of the dependent variable $y_{\text {(regional GDP). }}$

TABLE IV

MODEL SUMMARY ${ }^{\text {B }}$

\begin{tabular}{|c|c|c|c|c|}
\hline Model & $\mathrm{R}$ & R Square & Adjusted R Square & Std. Error of the Estimate \\
\hline dimension0 & $\begin{array}{ll}1 & .997 a\end{array}$ & .994 & .989 & 452.45331 \\
\hline
\end{tabular}

In the table of the variance analysis (Table 5), $F=211.243$, the significance horizontal probability of F's distribution is $P=0(\operatorname{sig} .=0.00)$, that is, the hypothesis testing of " $H_{0}$ :Regression coefficients $B=0$ " holds the probability of 0 , so that the null hypothesis should be rejected, which indicates that there is a significant linear relationship between the dependent variable and independent variables, and a linear model can be established.

TABLE V ANOVA ${ }^{\mathrm{B}}$

\begin{tabular}{lllllll}
\hline \multicolumn{2}{c}{ Model } & & & & & \\
& & Sum of Squares & df & Mean Square & F & Sig. \\
\hline 1 & Regression & $1.297 \mathrm{E} 8$ & 3 & $4.324 \mathrm{E} 7$ & 211.243 & $.000 \mathrm{a}$ \\
& Residual & 818856.002 & 4 & 204714.001 & & \\
& Total & $1.306 \mathrm{E} 8$ & 7 & & & \\
\hline
\end{tabular}

a. Predictors: (Constant), REGR factor score 3 for analysis 2, REGR factor score 2 for analysis 2, REGR factor score 1 for analysis 2

b. Dependent Variable: regional GDP y

In the table of model coefficients (Table 6), the horizontal probability of the $t$ 's distribution is $P=0($ sig. $=0.00)$, and the null hypothesis of the $t$ test should be rejected. It also indicates that there is a significant linear relationship between the dependent variable and the independent variables, and a linear model can be established. From Table 6, the regression equation is obtained as:

$$
y=16957.396+4153.837 F_{1}^{\prime}+1129.963 F_{2}^{\prime}-46.278 F_{3}^{\prime}
$$

TABLE VI COEFFICIENTS ${ }^{\mathrm{A}}$

\begin{tabular}{|c|c|c|c|c|c|c|c|}
\hline \multirow{2}{*}{\multicolumn{3}{|c|}{ Model }} & \multicolumn{2}{|c|}{ Unstandardized Coefficients } & \multirow{2}{*}{$\begin{array}{c}\begin{array}{c}\text { Standardized } \\
\text { Coefficients }\end{array} \\
\text { Beta }\end{array}$} & \multirow[b]{2}{*}{$\mathrm{t}$} & \multirow[b]{2}{*}{ Sig. } \\
\hline & & & B & Std. Error & & & \\
\hline 1 & (Constant) & & 16957.396 & 159.966 & & 106.006 & .000 \\
\hline & $\begin{array}{l}\text { REGR factor score } \\
\text { analysis } 2\end{array}$ & 1 for & 4153.837 & 171.011 & .962 & 24.290 & .000 \\
\hline & $\begin{array}{l}\text { REGR factor score } \\
\text { analysis } 2\end{array}$ & 2 for & 1129.963 & 171.011 & .262 & 6.608 & .003 \\
\hline & $\begin{array}{l}\text { REGR factor score } \\
\text { analysis } 2\end{array}$ & 3 for & -46.278 & 171.011 & -.011 & -.271 & .008 \\
\hline
\end{tabular}

a. Dependent Variable: regional GDP y

In order to further analyze the impacts of the original variable on the regional GDP, we substitute the factor score function (Equation (3)) obtained from the factor score matrix (Table 3) into the regression equation (Equation (4)) to obtain the model of relationship between Beijing's GDP and original variables. 


$$
y=16957.396+119.322 \quad x_{1}+447.903 \quad x_{2}+458.886 \quad x_{3}
$$$$
-348.914 x_{4}+458.885 x_{5}-460.334 x_{6}+179.804 x_{7}+335.098
$$

$$
\begin{array}{cc}
x_{8}-33.662 x_{9} & -470.327 x_{10}+288.772 x_{11}+446.544 x_{12} \\
& -407.731 x_{13}+445.055 x_{14}
\end{array}
$$

\section{2) Analysis of Environmental Protection and} Energy-Saving Results in Beijing

According to the linear regression model of Beijing (Equation (4)), it can be seen that Beijing's GDP is positively related to the main factors $F_{1}^{\prime}$ and $F_{2}^{\prime}$, where the basic factor $F^{\prime}{ }_{1}$ represents the industrial structure of the original variables $\left(x_{2}, x_{3}\right)$, the total amount of energy consumption and energy consumption level required for economic development $\left(x_{4}, x_{5}\right)$ and the amount of sulfur dioxide emissions $\left(x_{6}\right)$, scientific and technological development investment and achievements of industrial enterprises above the designated scale ( the amount of R\&D personnel $x_{11}$, the R\&D funds $x_{12}$ and the patent applications quantity $x_{13}$ ), the technology marketization level (the turnover $x_{14}$ ). The pressure factor $F_{2}^{\prime}$ mainly represents the completed investment for industrial pollution treatment $x_{1}$, the amount of smoke and dust emissions $x_{7}$, and the amount of household garbage removal $x_{8}$. The regression coefficients are in descending order, namely, the basic factor $F^{\prime}{ }_{1} 4153.837$, the pressure factor $F_{2}^{\prime} 1129.963$, and the ability factor $F_{3}^{\prime}$ -46.278, which indicates that the indicators represented by $F_{1}^{\prime}$ and $F^{\prime}{ }_{2}$ have a greater effect on the GDP in Beijing. It can also be seen that Beijing has to give top priority to the industrial structure, the total amount of energy consumption and its level, the amount of sulfur dioxide emissions, industrial enterprise researches, experimental development investment and results, and the marketization level. What's more, Beijing also should pay attention to the environmental pollution emission and its governance. However, not all the indicators represented by the above two main factors have contributed to the economic development of Beijing. It can be seen from the loading matrix after varimax orthogonal rotation (Table 2), some indicators have a large load on a major factor but they are negative, which indicates that they have negative correlations with the main factor. For example, the total amount of energy consumption $x_{4}$ and the amount of sulfur dioxide emissions $x_{6}$ are negatively correlated with the main factor $F_{1}^{\prime}$, and the amount of smoke dust emissions $x_{7}$ are negatively correlated with the main factor $F_{2}^{\prime}$. From equation (5), it can also be seen that the coefficients of the two variables $x_{4}$ and $x_{6}$ are negative, indicating that the increase in these quantities will impede the increase of the GDP in
Beijing. Although $x_{7}$ is negatively correlated with the main factor $F_{2}^{\prime}$, it is positively correlated with another main factor $F_{1}^{\prime}$ and their coefficients are not so much different, the coefficient of $x_{7}$ in equation (5) is positive. In the regression equation, the coefficient of the main factor $F_{3}^{\prime}$ is negative, which indicates that $F_{3}^{\prime}$ is negatively related to Beijing's GDP. We name $F_{3}^{\prime}$ the capacity factor, which represents $x_{9}$, the quantity of garbage innocuity disposal (taking 10 thousand ton as the unit) and $x_{10}$, the comprehensive utilization amount of general industrial solid waste, both of which are positively related to $F_{3}^{\prime}$. It seems unreasonable that prominent environmental treatment capacity and great waste utilization should promote economic development. However, considering from another perspective, a large amount of waste disposal also indicates a large number of emissions, which needs to be handled and utilized by a certain number of human and financial resources, thereby consuming social resources.

\section{CONCLUSION AND SUGGESTIONS}

\section{A. Conclusion}

The regression analysis of Beijing's statistical data shows that Beijing's GDP is closely related to industrial structure, science and technology, industrial pollution investment and the relationship between energy and pollution emissions. Therefore, we should make a scientific layout for the industrial structure and development, attach importance to environmental protection and governance, and encourage the growth of environmental protection enterprises.

\section{B. Policies and suggestions}

Environmental investment can balance the coordinated economic growth and environmental protection. It is an important support force for solving environmental problems and plays a significant role in building a harmonious society and realizing sustainable development [8]. The government should increase environmental investment, encourage the growth of advanced energy-saving products and technologies, and develop the environmental protection industry. What's more, the government should formulate more stringent environmental laws and regulations, enhance the environmental awareness of enterprises and individuals, and reduce environmental pollution. On top of that, it also should make full use of the advantages in Beijing, establishing an integrated system of production, study and research, and cultivating talents in environmental protection technology.

\section{REFERENCES}

[1] Liu Jianqiu, Lan Guoqian, Guolijian, Zhangjiangwei. Investigation and Analysis on Development of Environmental Protection Industry in Hebei Province [J]. Management \& Technology of SME (late edition), 2014, (12):131-133.

[2] http://finance.sina.com.cn/china/20151102/222723655477.shtml 
[3] Zhang Qiongzhi. Study on the Factors Influencing the Growth of China's Energy-saving and Environmental-friendly Listed Companies [D]. Anhui University, 2013.

[4] Yang Wensheng. Research on the Development of Environmental Protection Industry [D]. Huazhong Agricultural University,2005

[5] Liu Yifeng. The Development Situation and Countermeasure Research Of Energy Saving and Environmental Protection Industry In Guangzhou [J].Guangdong Economy, 2015, (01):68-72.

[6] Tao Jin. Research on Influential Factors of Energy Saving and Environmental Protection Industry In China [D]. Anhui University of Finance and Economics, 2015.

[7] Tan Rongbo, Mei Xiaoren. Practical Course of SPSS Statistical Analysis [M].Beijing: Science Press, 2007.

[8] Zhu Jingran, He Lingyun, Zhu Yei. Research on Comprehensive Benefits of Environmental Protection Investment in China from the Perspective of Classification [J]. Ecological Economy, 2014,(01):107-114. 